\title{
Stretchable current collectors based on carbon embedded in a poly (acrylamide)/poly ( $N, N$-methylenebisacrylamide) hydrogel modified with Nafion $117^{\circledR}$
}

\author{
Mariusz Radtke ${ }^{1} \cdot$ Anna Ignaszak ${ }^{1}$
}

Received: 22 April 2018 / Accepted: 12 October 2018 / Published online: 22 October 2018

(c) The Author(s) 2018

\begin{abstract}
In this study, we optimized the dispersion of hydrophobic carbons within ionically conductive hydrogels composed of a poly (acrylamide)-pAAm/poly ( $N, N$-methylenebisacrylamide)-pMBAA modified with Nafion $117^{\circledR}$. The carbon-embedded hydrogel films were prepared by in situ UV polymerization of aqueous suspension containing $\mathrm{KCl}$, acrylamide and $N, N$ methylenebisacrylamide monomers, the multi-walled-carbon nanotubes, graphene, single-walled carbon nanohorns, and their composites with polypyrrole. These electrodes were translucent, stretchable, ionically and electronically conductive at low carbon content. In addition, they were very flexible, reaching a stretch up to $1475.57 \%$ of their initial length. Mechanical characteristics and conductivity were measured at their maximum hydration, corresponding to water uptake of $47.20 \%$ after 5 days of curing in humidity chamber. Hydrogels with dispersed carbon demonstrated both ionic and electronic conductivity in hydrated state and electronic conductivity alone when the electrode was dry. Nafion $117^{\circledR}$ acted as a surfactant and played a significant role in the improvement of carbon distribution within the hydrogel due to the hydrophobic-hydrophilic interaction between hydrogel, Nafion and the carbon. This was further correlated with changes in zeta potential at the carbon-hydrogel interface upon addition of Nafion, measured using a rotating disk electrode voltammetry.
\end{abstract}

\section{Graphical abstract}

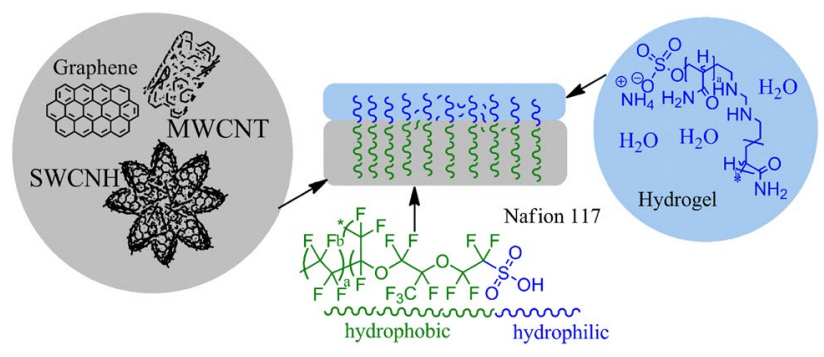

Keywords Poly(acrylamide) hydrogels $\cdot$ Conductivity $\cdot$ Carbon dispersion · Impedance

Electronic supplementary material The online version of this article (https://doi.org/10.1007/s40243-018-0137-5) contains supplementary material, which is available to authorized users.

Anna Ignaszak

Anna.Ignaszak@unb.ca

1 Department of Chemistry, University of New Brunswick, 30 Dineen Drive, Fredericton, NB E3B 5A3, Canada

\section{Introduction}

Polyacrylamide-based hydrogels are important components of portable electronics, decontamination agents, separation membranes, hygienic products, sealing, coal dewatering mediators, wound dressings and biosensors [1-8]. They have been also successfully applied as an elastic platform for electrodes used in light-weight capacitors [9]. The easiness of synthesis and excellent mechanical properties are their 
major advantages, however improving their electrical properties, while retaining mechanical characteristics remains still challenging. One way to increase the conductivity of polyacrylamide-based electrodes is to pair them with more conductive materials. For example, hydrogels containing MWCNTs, graphene or other carbons showed both very good electrical and mechanical features that are especially needed in energy reposition area [10]. Nevertheless, there are still few technical challenges that restrict their utilization, such as their poor solubility in common solvents and dispersion of various active components within the hydrogel [11].

The carbonaceous materials such as carbon nanotubes (single-, double- or multi-walled) are prone to agglomerate due to the van der Waals interaction and $\pi-\pi$ stacking between carbon particles and this problem cannot be solved by common laboratory techniques, such as sonication [12]. The attractive van der Waals forces in the single-walled carbon nanotubes (SWCNHs) are estimated to be in the range of $500 \mathrm{eV}$ per micrometer of tube-to-tube contacts [11]. The good dispersion of carbon, especially structures like nanotubes or graphene, is needed to fully utilize their functions in hydrogels [13]. The nanodispersion of carbonaceous materials can be analyzed by several techniques, such as the optical fluorescence spectroscopy, a small-angle X-ray scattering, or deuterium solid-state nuclear magnetic resonance [14, 15]. These techniques allow to control an extent of homogeneity and to optimize it with respect to the composition of carbon-embedded hydrogels [16]. Yet, poor dispersion of carbons in aqueous solution and within hydrogels is related to their hydrophobic nature [17]. One of the most common methods for improving homogeneity of carbon suspension (in both liquids and hydrogels) is to apply surfactants or other additives [18, 19]. Overall, the methods of improving homogeneity of carbon are categorized as a covalent and non-covalent functionalization of carbons $[12,20]$. As an example of covalent functionalization, it has been shown that appropriate chemical surface modification of carbon nanotubes with oxygen-containing moieties (oxalic, carboxylic, phenolic) can improve their dispersion in common solvents $[21,22]$. Regarding the hydrogel-embedded carbons, it has been demonstrated that agglomerated carbon introduces local defects into the polymer, which significantly reduces its mechanical and electrochemical characteristics [23, 24]. The non-covalent modification refers to applying ionic surfactants such as the sodium dodecyl benzene carbonate (NaDDBS) or cetyl trimethylammonium bromide (CTAB), which can enhance the dispersion of carbons in both organic (isopropyl alcohol- $\mathrm{iPrOH}$ ) and aqueous solutions [25, 26].

Also, it has been postulated that homogeneity of carbon suspension depends on charge distribution at the carbon/solvent interface [27] and the interaction between polarized layers is defined by hydrodynamic shear factor known as zeta $(\xi)$-potential [28]. This potential depends on the chemical properties of both particle surface and solution composition (i.e., $\mathrm{pH}$ ). The $\mathrm{pH}$ value corresponding to $\xi=0 \mathrm{mV}$ is known as the isoelectric point (IEP) and, when the magnitude of the zeta potential is close to the IEP or smaller than a certain threshold, the repulsive forces between particles are weak and particle agglomeration occurs. The measurement of zeta potential offers a link between experiments and theoretical background. In particular, zeta potential is often associated with the value of electrical surface potential, $E_{\mathrm{tot}}=E_{\mathrm{VW}}+E_{\text {Elec }}$ (where). This interparticle energy depends on the sum of attractive and repulsive interactions, which are both functions of the particle distance. The London-van der Waals contribution, $E_{\mathrm{VW}}$, between two particles of the same material is always attractive, thus promoting the aggregation of suspended particles. Instead, the repulsive component, $E_{\text {Elec }}$, can be explained by recalling the electric double-layer formation, i.e., the chemical phenomena occurring on the particle surface in a polar host fluid. In such conditions, the nanoparticle develops a surface charge according to the particle material. For example, in colloidal suspension of functionalized carbon-based particles dispersed in water, a negative surface charge is developed on the particle's surface by the ionization of the surface groups (e.g., $-\mathrm{COOH})$. Because of the surface charge, an electrostatic potential is created in the proximity of nanoparticle, and a concentrated layer of counter ions, known as Stern layer, is formed. As a result, the zeta potential at the carbon surface exceeds the total interaction potential barrier $\left(E_{\mathrm{tot}}\right)$, and at given distance the particle repelling is stronger than attractive than van der Walls forces, resulting in the formation of homogeneous suspensions [29]. An interesting phenomenon occurs during sonication of the carbon nanotube suspension in aliphatic solvent, when van der Waals forces between carbon sheets are broken, resulting in a local shear at the carbon-carbon contact, allowing the solvent to penetrate within agglomerated carbon particles [30]. Further study has shown that carbon nanotubes possess small negative zeta potential in aqueous solution and it varies depending on their purification method and an extent of surface functionalization [31].

A model that describes charge distribution at the carbon/surfactant interface is defined by Smoluchowski equation that correlates dynamic shear viscosity of surfactant and the surface tension with change of zeta potential [32]:

$\xi=\frac{\mu \sigma}{\varepsilon \varepsilon_{0}} \frac{\Delta V}{\Delta P}$

where $\xi$ represents zeta potential $(\mathrm{mV}), \mu$ is the dynamic shear viscosity (mPa s), $\sigma$ is the conductivity of the solution, $\varepsilon \varepsilon_{0}$ is the permittivity $\left(\mathrm{F} \mathrm{m}^{-1}\right), V$ is the voltage $(\mathrm{V})$ and $P$ is the pressure $(\mathrm{Pa})$. 
The charged surfactants bearing long hydrophobic aliphatic chains and hydrophilic anionic groups generate an electrical double layer at the carbon surface [33]. The formation of this double layer results in lowering the zeta potential at the surfactant surface (more negative zeta potential is preferred). As a consequence, nanotubes with adsorbed surfactant repel each other, leading to stabilization of the colloidal solution [11]. In addition, surfactants with long hydrophobic chains generate strong hydrophobic-hydrophobic interactions between the graphitized carbon surface and the alkyl chain. The presence of anionic head in the surfactant is believed to be the most significant merit in lowering zeta potential of nanotubes. Further investigation also revealed an improvement in the carbon dispersion between cationic and anionic groups when mixed with surfactants with long hydrophobic alkyl chains $[15,34]$. Yet, anionic surfactants are more efficient in lowering zeta potential as they are bigger in size in comparison with cationic functionalities [35]. Also, smallangle neutron scattering experiments suggested that carbon nanotubes are only partially covered by the surfactant molecules [36]. This indicates that the mechanism of carbon dispersion implies changes in zeta potential of surfactant adsorbed at the carbon surface [36].

The recent studies have shown improvement in homogeneity of carbon nanotube and graphene suspensions in the presence of Nafion $117^{\circledR}$ [37-39]. The structure of Nafion $117^{\circledR}$ is presented in Fig. 1 (insert B) and is formed from $\mathrm{R}-\mathrm{SO}_{3} \mathrm{M}$ units, where $\mathrm{R}$ is a long perfluorated aliphatic chain and $\mathrm{M}$ is the cation that counterbalances negative charge located on the sulfonic group. There are several benefits of having Nafion in carbon suspension. Listing one, it strongly lowers zeta potential on nanotubes in isopropanol suspensions [28]. An excellent ionic conductivity of Nafion $117^{\circledR}$ is another advantage and leads to improvement of electrochemical response (i.e., double-layer capacitance) of dispersed nanotubes [40, 41]. This is related to the formation of percolated water channels that facilitate proton transport via a vehicular mechanism, which was analyzed by small angle neutron scattering (SANS) [42]. These studies have revealed that water pools trapped between the polymer are very active and they dilute under the stress. As a consequence, sulfonated chains of Nafion start to form organized crystal structures with locally lower conductivity [42]. The appropriate content of water leads to good control over the deformation rate of Nafion upon applied stress. This appeared to be important in flexible electrodes proposed in this study.

The elastic electrodes used in portable electronics, smart textiles and wearable technologies require good mechanical stretch $[43,44]$. In addition to that, flexible energy storage devices are considered as emerging technology [45]. Many active materials used in capacitors such as carbon or conjugated polymers were dispersed within the poly(acrylamide)/poly ( $N, N$-methylenebisacrylamide). An excellent dispersion of conjugated polymers within the acrylamide framework was achieved by simultaneous co-polymerization of functionalized monomers [46, 47].
Fig. 1 A photo-initiated synthesis of hydrogel-embedded carbon electrode (with the multi-walled carbon nanotubes as an example) a The formation of hydrophilic/hydrophobic interface between carbon, hydrogel, Nafion $117^{\circledR}$ and water b
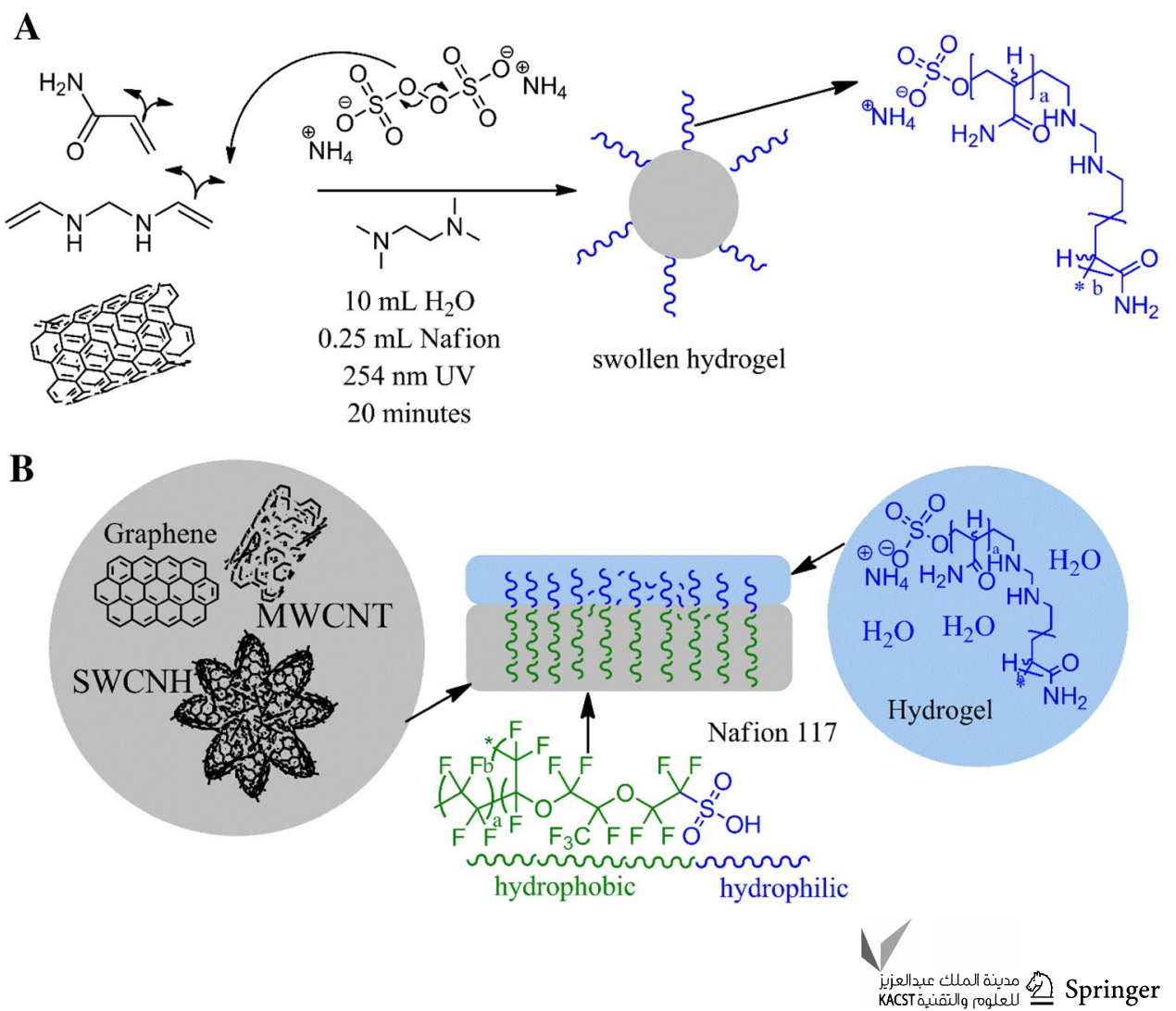
Another important feature sought in conductive hydrogels is their transparency. This is strongly influenced by the type of carbon (graphene is preferred for translucent electrodes rather than carbon blacks), and the carbon distribution within polymer.

In this work, we demonstrate that small addition of Nafion $117^{\circledR}$ solution leads to improvement in dispersion of various carbon allotropes, including graphene, multiwalled carbon nanotubes (MWCNT), single-walled carbon nanohorns (SWCNHs) and their composites with polypyrrole within poly(acrylamide)/poly $(N, N$-methylenebisacrylamide) hydrogels. The stretchable, translucent (with 0.1-2 wt $\%$ of carbon or carbon-grafted-polypyrrole) hydrogel films were prepared by the UV-initiated frontal polymerization of an aqueous suspension containing acrylamide $/ N, N$ methylenebisacrylamide monomers, nanostructured carbons (and their composites with PPy), potassium chloride and Nafion $117^{\circledR}$. An ammonium persulfate (APS) was used as an initiator for photopolymerization. The conductivity and interfacial capacitance of elastic films were investigated by an alternating current electrochemical impedance and admittance spectroscopy (AC EIS/EAS). The thermal gravimetric analysis (TGA), Fourier-transform infrared spectroscopy (FTIR), Raman spectroscopy, the field emission scanning electron microscopy (FESEM), optical observations and the stress-strain mechanical testing were employed for material characterization. The rotating disk electrode voltammetry allowed to estimate the streaming potential that was further used to approximate zeta potential for various configurations of coatings, such as a background electrode (bare disk, disk coated with hydrogel only), and upon addition of Nafion $117^{\circledR}$ and carbon. Furthermore, we discussed the possible mechanism underlying enhanced conductivity within Nafion $117^{\circledR}$ modified laminates and proposed an easy method for their upscaling.

\section{Experimental}

\section{Materials and methods}

Unless otherwise stated all materials were used as received without further purification. Acrylamide (AAm) (>99\% HPLC purity), $N, N$-methylenebisacrylamide (MBA), singlewalled carbon nanohorns (as-grown, 804,118 Aldrich, BET $400 \mathrm{~m}^{2} \mathrm{~g}^{-1}$ ), multi-walled carbon nanotubes ( $95 \%$ carbon, 724,769 Aldrich, BET $220 \mathrm{~m}^{2} \mathrm{~g}^{-1}$ ), poly(vinylidene difluoride) with an average molecular weight of 180.000 , potassium bromide (FTIR grade), and potassium chloride (analytical grade, p.a., C99.5\%) were purchased from Aldrich, and graphene flakes (12 nm flakes AO-3) from Graphene Supermarket. TEM imaging was carried out using a Jeol 2100 sTEM operating at $200 \mathrm{kV}$; FTIR spectra on a $\mathrm{KBr}$ pellet were recorded with the NicoletTM iSTM 50 FTIR, $4 \mathrm{~cm}^{-1}$ resolution, 100 scan per sample ( $\mathrm{KBr}$ was dried in oven at $80{ }^{\circ} \mathrm{C}$ prior to the use). The Raman spectroscopy was carried out on the Renishaw inVia Raman spectrometer at 785 and $514 \mathrm{~nm}$ excitation sources (Renishaw Inc., UK) in the spectral range from 1000 to $3000 \mathrm{~cm}^{-1}$, at $0.1 \mathrm{~mW}$ laser power, using 50 times magnification on the microscope. All electrochemical experiments were done using the $\mathrm{CH}$ Instruments electrochemical workstation model C760 in a two-electrode cell consisting of $20 \times 20 \mathrm{~mm}$ stainless-steel plates as current collectors. The alternating current impedance/admittance spectra were acquired using the same electrochemical setup and analyzed and fitted with ZView software (Scribner Associates, USA). For the electrochemical analysis of zeta potential, the glassy carbon rotating disk electrode $\left(0.1963 \mathrm{~cm}^{2}\right.$, Pine Instrumentation) was coated with a mixture of MWCNT, hydrogel and Nafion. In all the experiments, $5 \mathrm{~mL}$ of suspension consisting of the same amount of carbon, hydrogel, isopropanol and various Nafion content was deposited onto the glassy carbon $\mathrm{RDE}$ and dried in the air. The electrode was mounted in a three-electrode cell ( $\mathrm{Pt}$ wire was used as counter and $\mathrm{Ag}$ / $\mathrm{AgCl}(E=0.222 \mathrm{~V}$ vs. SHE) as the reference electrode, as shown in Figure S9) and filled with $50 \mathrm{~mL}$ of deionized and degassed water. The open circuit potential was recorded under rotation speed of 400 or $900 \mathrm{rpm}$ with the electrode rotor Pine Instrumentation model AFMRSCE. The thermal analysis was carried out using TGA Q500 model TA Instruments from 25 to $650{ }^{\circ} \mathrm{C}$ at the heating rate of $10{ }^{\circ} \mathrm{C} \mathrm{min}^{-1}$ in $N_{2}$ using $100 \mathrm{~mL}$ alumina crucible. The Field Emission Scanning Electron Microscopy imaging was performed on the Hitachi SU-70 Field Emission Gun (FEG) SEM scope. All mechanical tests were conducted using the Tinius Olsen 2000 tensile strength universal testing machine equipped with $1 \mathrm{kN}$ load cell under air, and the elongation rate was kept as $40 \mathrm{~mm} \mathrm{~min}^{-1}$. The UV-crosslinking was performed with the UV-crosslinker (VWR) equipped with a microprocessor controlled UV sensor feedback system at the energy irradiation exposure of $300,000 \mu \mathrm{J} \mathrm{cm}{ }^{-2}$ for $20 \mathrm{~min}$.

For testing of water uptake (WU), as-prepared sample was weighted giving an initial mass $\left(m_{0}\right)$ and placed in a closed vessel at constant relative humidity and temperature. The electrode was weighed in time intervals (every $24 \mathrm{~h}$ ) and water uptake (WU) was calculated from the ratio of initial mass and after curing in the presence of water vapor.

\section{Synthesis}

$50 \mathrm{~mL}$ of deionized water was purged with dry nitrogen for $30 \mathrm{~min}$ prior use. In two separate vials, the respective amounts of material were prepared; in first vial $0.0256 \mathrm{~g}$ of ammonium persulfate was dissolved in $1 \mathrm{~mL}$ of deionized water, and in the second $1.56 \mathrm{~g}$ acrylamide, $1.18 \mathrm{~g}$ potassium 
chloride, $0.5 \mathrm{~mL}$ of Nafion $5 \mathrm{wt} \%$ stock solution, $0.05 \mathrm{~mL}$ tetramethylethylenediamine (TEMED), and $0.001 \mathrm{~g}$ of active material (graphene, MWCNTs, SWCNHs or grafted with PPy; synthesis of the latest compounds is a subject of our previous work) were mixed with $9 \mathrm{~mL}$ of deionized water and sonicated for $30 \mathrm{~min}$ (until $\mathrm{KCl}$ dissolves). All procedures were performed under inert atmosphere. Both mixtures were combined and stirred for about $10 \mathrm{~s}$; afterwards, the suspension was poured onto the Petri dish and placed in UV-cross linker for 20 min irradiation under air.

Figure 1a demonstrates steps in the synthesis of stretchable hydrogels containing nanostructured carbon allotropes (graphene, MWCNTs or SWCNHs). Briefly, acrylamide was photochemically cross-linked with $N, N$-methylenebisacrylamide in the presence of ammonium persulfate as the photoinitiator, tetramethylethylenediamine (crosslinking agent), potassium chloride and Nafion $117^{\circledR}$ as additives. Since TEMED accelerates polymerization as shown in a detailed mechanism in Figure S1 (supporting information), a doubled molar ratio between APS and TEMED was kept in our procedure [48]. A new aspect of this synthesis is using Nafion $117^{\circledR}$, in which function is to improve dispersion of carbon in aqueous mixture of monomers. In the presence of Nafion, surface tension of nanostructured carbons is modified in their aqueous suspension, resulting in better homogeneity of this mixture and, thus, in uniformity of the elastic electrode. The dispersion was validated visually and by means of the field emission scanning electron microscope imaging for dry hydrogels (Figure S6).

\section{Results and discussion}

\section{Molecular interactions within hydrogel components}

Figure $1 \mathrm{~b}$ demonstrates the formation of hydrophobic/hydrophilic interface between carbon, hydrogel and Nafion. The mechanism of interaction between these compounds relies on two processes, one is the affinity of hydrophobic fractions (carbon and tetrafluoroethylene chain of Nafion, marked in green color in Fig. 1b), and the second are coulombic interactions of positively charged chain of Nafion $117^{\circledR}$ with water encapsulated within polyacrylamide (marked in blue color in Fig. 1b). The stacking of aliphatic chain of Nafion $117^{\circledR}$ at the graphitized carbon surface leads to lowering zeta potential on carbon surface. This results in a repulsion between the carbon particles (which are prone to severe agglomeration in pure aqueous solution), and in the formation of homogenous colloidal suspension of carbon. The structure of Nafion $117^{\circledR}$ is displayed in Fig. 1b, with water-compatible, sulfonic head marked in blue and the hydrophobic chain in green. Similar mechanisms of interaction between Nafion and the carbon were proposed
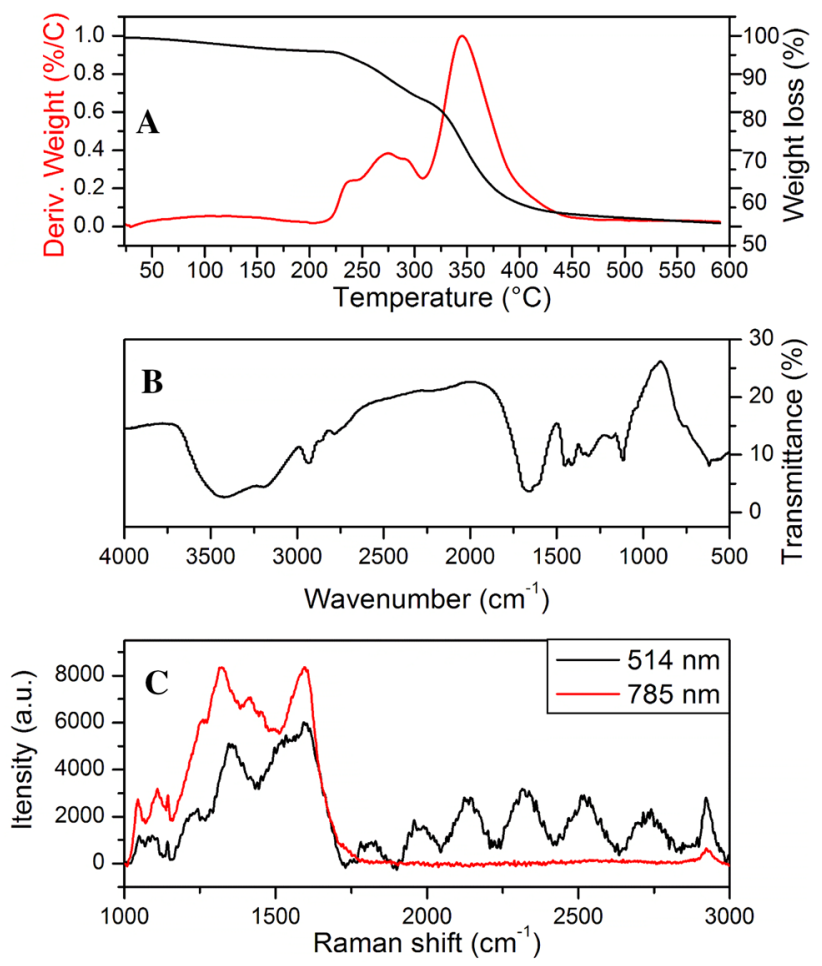

Fig. 2 TGA of MWCNT-embedded hydrogel a, FTIR spectrum of Graphene-embedded hydrogel b, Raman spectra at the light sources of 514 and $785 \mathrm{~nm}$ for the MWCNT-embedded hydrogels $\mathbf{c}$

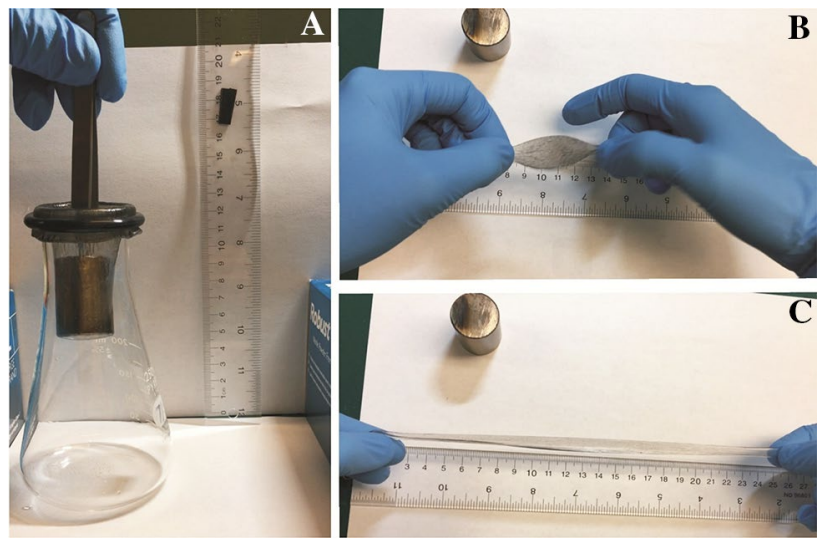

Fig. 3 Stretching tests of transparent graphene-based hydrogel with weight standard a, stretching of the same hydrogel film (b and $\mathbf{c}$ )

earlier $[11,49,50]$. The affinity of hydrophobic surface of carbon and tetrafluorocarbon from Nafion has been considered as a major reason for improvement of the carbon dispersion within the polymer. Two different concepts were also proposed by other groups, one states the entropic repulsion of carbon particles in Nafion solution, and the second correlates the carbon-Nafion interaction with coulombic processes such as a formation of electrical double layer at the carbon/polymer interface. As a result, repulsion

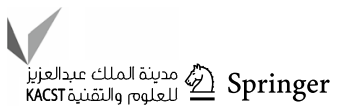


between polymer-coated carbon particles takes place due to the presence of sulfonic groups (negatively charged) at the outermost shell of Nafion-coated carbon. This process is further enhanced in the presence of poly (acryl amide)/poly ( $N, \mathrm{~N}$-methylenebisacrylamide) hydrogel containing water encapsulated in its structure (since these hydrogels absorb up to $47.20 \mathrm{wt} \%$ water as shown in following section in Fig. 4a). Thus, the Nafion-coated carbon in such hydrogel medium behaves similar as it will be suspended in the aqueous solution.

\section{Spectroscopic and thermal characterization}

Figure 2a shows thermal gravimetric scan of the MWCNTcontaining dry hydrogel and the first derivative of weight loss (in \%) as the function of applied temperature, revealing the most important transitions during the combustion of polymers. An initial decomposition temperature (IDT) is detected at $235.67{ }^{\circ} \mathrm{C}$ and the final decomposition temperature (FDT) at $246.79^{\circ} \mathrm{C}$, resulting in $5.64 \%$ weight loss, was attributed to the degradation of pure and not cross-linked acrylamide monomer. Afterwards, decomposition of pure and not cross-linked poly (acrylamide) corresponding to $5.72 \%$ weight loss began at IDT of $251.88{ }^{\circ} \mathrm{C}$ and FDT of $287.53{ }^{\circ} \mathrm{C}$. A weak signal related to $3.92 \%$ weight loss was attributed to the decomposition of Nafion and starts at $287.53{ }^{\circ} \mathrm{C}$ IDT and ends at $314.09{ }^{\circ} \mathrm{C}$ FDT. The main
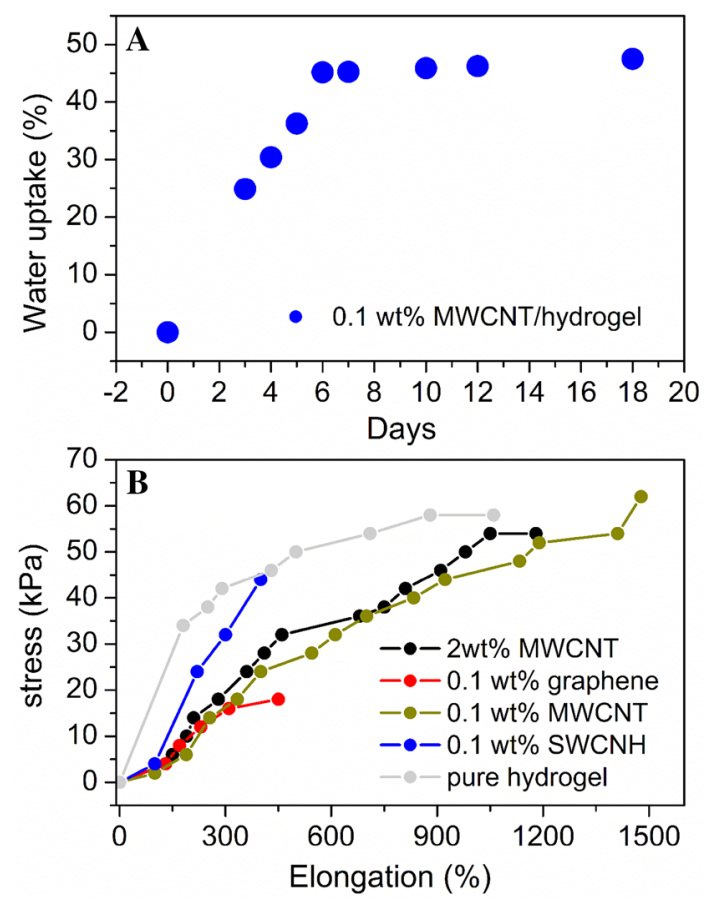

Fig. 4 Water uptake of dehydrated hydrogel placed in a closed container with water at $19.0{ }^{\circ} \mathrm{C} \mathrm{a}$; the elongation test of carbon-embedded and pure hydrogel electrodes at load of $1 \mathrm{kN} \mathrm{b}$ decomposition of the poly (acrylamide) cross-linked with MBA $(N, N$-methylenebisacrylamide) with $26.72 \%$ weight loss showed onset temperature at $307.39{ }^{\circ} \mathrm{C}$ that ended at $444.24{ }^{\circ} \mathrm{C}$ FDT. TGA scans for hydrogels containing other carbon allotropes followed the same decomposition steps and temperatures corresponding to particular transitions were almost the same for all carbons. Thus, at given carbon loading (taking into account 99.9 wt \% taken by hydrogel), thermal effects are considered to be mostly from polymer fractions and are not influenced by the type of carbon.

Figure $2 b$ demonstrates the FTIR spectrum of graphenecontaining hydrogel with distinct signals assigned to acrylamide-based polymers. Due to significant overlapping in the aliphatic region, it was difficult to distinguish between the $\mathrm{CH}_{2}$ and $\mathrm{C}-\mathrm{C}$ wagging of the poly (acrylamide)/poly (MBAA) backbones and graphene. The FTIR spectra for all carbon-embedded hydrogels were similar and corresponded to hydrogel signals. Similar to TGA analysis, FTIR showed only signals related to polymers, which were not influenced by the presence of various carbon allotropes at given carbon loading. Peaks at 1113.22 and $1350.93 \mathrm{~cm}^{-1}$ corresponded to the $\mathrm{C}-\mathrm{O}$ stretch and at $1181.04 \mathrm{~cm}^{-1}$ were assigned to the $\mathrm{C}-\mathrm{N}$ stretch, together with the $\mathrm{N}-\mathrm{H}$ vibration at $2940.52 \mathrm{~cm}^{-1}$. The vibrations at $1316.66,1401.97$, $1461.77,2761.87,2855.20 \mathrm{~cm}^{-1}$ corresponded to the $\mathrm{C}-\mathrm{H}$ bonding, arising from amines and amides present in the hydrogel structure. The band at $1606.14 \mathrm{~cm}^{-1}$ was related to the $\mathrm{C}=\mathrm{C}$ vibration and the band at $1679.97 \mathrm{~cm}^{-1}$ was a signal of unreacted carbon double bonds from AAm and MBAA monomers. Also, the amide stretch was observed at $3442.19 \mathrm{~cm}^{-1}$ and the $-\mathrm{OH}$ stretch at $3178.22 \mathrm{~cm}^{-1}$. The FTIR and Raman signals are shown in Table 1. An attempt was made to distinguish between the nanostructured carbon and hydrogel by Raman spectroscopy. The presence of Raman shifts assigned to carbon's D and G bands was analyzed at different laser wavelengths (514 and $785 \mathrm{~nm}$ ). This allowed better insight into hydrogel and carbon structures, as the intensity of Raman scattering is directly proportional to energy of incident laser [51]. Shorter wavelengths are suitable for analysis of the carbon structure, whereby longer wavelengths are appropriate for Raman shifts of the polymer [52]. Figure 2c shows clearly shifts in D and G bands observed at both laser wavelengths, which were possibly caused by the overlap of signals from the polymer backbone with graphene response [53]. The Raman spectra for pristine graphene and pristine hydrogel can be found in supporting information, Figures S2 and S4. The presence of 2D peaks at both laser wavelengths indicates agglomeration of graphene sheets and is a useful tool for validating the dispersion using spectroscopic method [54]. In this analysis, we applied the Ferrari-Robertson relation that describes the change in shape between $\mathrm{G}_{\text {apparent }}$ (Fig. 2c, $1600.42 \mathrm{~cm}^{-1}$ ) and 2D peaks (Fig. 2c, $2713.14 \mathrm{~cm}^{-1}$ ) and their respective 
Table 1 FTIR and Raman analysis of Graphene-grafted-PPy embedded in hydrogel

\begin{tabular}{|c|c|c|c|c|c|}
\hline FTIR band $\mathrm{cm}^{-1}$ & Assignment & $\begin{array}{l}\text { Raman shift at } \\
514 \mathrm{~nm} \mathrm{~cm}^{-1}\end{array}$ & Assignment & $\begin{array}{l}\text { Raman shift at } \\
785 \mathrm{~nm} \mathrm{~cm}^{-1}\end{array}$ & Assignment \\
\hline 1113.22 & $\mathrm{C}-\mathrm{O}$ stretch & 1051.66 & $-\mathrm{SO}_{4}{ }^{2-} / \mathrm{HSO}_{4}^{-}$ & 1046.66 & $-\mathrm{SO}_{4}{ }^{2-} / \mathrm{HSO}_{4}^{-}$ \\
\hline 1181.04 & $\mathrm{C}-\mathrm{N}$ stretch & 1105.00 & Sym. CH bend & 1110.00 & Sym. CH bend \\
\hline 1121.25 & $\mathrm{C}-\mathrm{O}$ stretch & 1143.75 & $-\mathrm{CH}_{2}$ deform. & 1260.12 & $-\mathrm{CH}_{2}$ deform. \\
\hline 1316.66 & $\mathrm{C}-\mathrm{H}$ vibration & 1236.25 & Amide II & 1323.75 & $\mathrm{D}$ \\
\hline 1350.93 & $-\mathrm{OH}$ vibration & 1352.91 & $\mathrm{D}$ & 1415.83 & Amide II \\
\hline 1401.97 & $\mathrm{C}-\mathrm{H}$ vibration (amine) & 1537.50 & $-\mathrm{C}=\mathrm{C}-$ conjugated & 1459.58 & $-\mathrm{C}=\mathrm{C}-$ conjugated \\
\hline 1461.77 & $\mathrm{C}-\mathrm{H}$ vibration (amine) & 1600.42 & $\mathrm{G}_{\text {apparent }}^{\prime}$ & 1595.83 & $\mathrm{G}_{\text {apparent }}^{\prime}$ \\
\hline 1606.14 & $\mathrm{C}=\mathrm{C}$ vibration & 2713.41 & $2 \mathrm{D}$ & 2921.66 & $2 \mathrm{D}$ \\
\hline 1673.97 & $\mathrm{C}=\mathrm{C}$ vibration $(\mathrm{MBAA})$ & - & - & - & - \\
\hline 2761.87 & $\mathrm{C}-\mathrm{H}$ vibration & - & - & - & - \\
\hline 2855.20 & $\mathrm{C}-\mathrm{H}$ vibration (amide) & - & - & - & - \\
\hline 2940.52 & $\mathrm{~N}-\mathrm{H}$ vibration & - & - & - & - \\
\hline 3178.22 & $-\mathrm{OH}$ stretch & - & - & - & - \\
\hline 3442.19 & Amide NH- stretch & - & - & - & - \\
\hline
\end{tabular}

Raman shifts [54]. The presence of 2D peak of graphene is caused by the development of electron-phonon interactions due to the accumulation of graphene layers. The relative intensity of 2D peak correlates with a number of overlaying graphene sheets [55]. The 2D Raman peak is composed of four components representing the electron-phonon coupling and labeled as $2 \mathrm{D}_{1 \mathrm{~B}}, 2 \mathrm{D}_{1 \mathrm{~A}}, 2 \mathrm{D}_{2 \mathrm{~A}}$ and $2 \mathrm{D}_{2 \mathrm{~B}}$ (Figure S5, supporting information). Therefore, the comparison of $I_{\mathrm{G}} / I_{2 \mathrm{D} 1 \mathrm{~A}}$ intensities allowed to estimate the number of overlaying layers. Figure $2 \mathrm{c}$ demonstrates that intensity of $2 \mathrm{D}_{2 \mathrm{~A}}$ peak at $514 \mathrm{~nm}$ is considerably larger and is caused by contribution of overlapped graphene sheets to Raman spectrum; it is also shown in the spectrum recorded at $785 \mathrm{~nm}$. At the laser wavelength of $785 \mathrm{~nm}$, there are peaks at Raman shifts resembling the pristine hydrogel (e.g., $I_{\mathrm{G}} / I_{2 \mathrm{D} 1 \mathrm{~A}}$ intensities of 1495.83/1496.15, 1452.5/1496.36, 1412.91/1417.87 for Raman shifts observed, respectively, for the graphenecontaining hydrogel and pristine pAAm/pMBAA hydrogel, Fig. 2 and Figure S5, supporting information). The ratio of $I_{\mathrm{G}}$ 'apparent $/ I_{2 \mathrm{D} 1 \mathrm{~A}}$ peaks at $514 \mathrm{~nm}$ is considerably larger for dry hydrogel (12.98), as compared to the pristine graphene (5.77).

The analysis of intensity ratio of $\mathrm{G}^{\prime}{ }_{\text {apparent }} / 2 \mathrm{D}_{1 \mathrm{~A}}$ signals, indicating possible agglomeration of multi-walled carbon nanotubes or single-walled carbon nanohorns did not show obvious differences, as observed for graphene. This demonstrates that the phonon-electron interactions in these structures are believed to be of different nature [56].

TGA analysis indicated that some non-polymerized MBAA and AAm are also identified in the electrode. This was further confirmed by the presence of Raman shifts at 1537.50 and $1459.59 \mathrm{~cm}^{-1}$. These signals are assigned to conjugated double bonds in MBAA structure. Both gravimetric and spectroscopic studies demonstrated qualitatively the differences between pristine hydrogel and its combination with nanostructured carbons. Overall, hydrogels containing SWCNH, MWCNT or graphene did not show significant difference when tested using TGA and Raman spectroscopy. The Raman spectroscopy carried out at various wavelengths was the most suitable technique to detect subtle structural differences of the carbon suspended in hydrogel. Particularly, it was useful to analyze the dispersion of carbon (overlapping of carbon particles).

\section{Morphology}

Optical observations are presented in Fig. 3. Figure 3b shows the hydrogel with dispersed graphene (at the carbon content of $0.1 \mathrm{wt} \%$ ). This image demonstrates that an electrode with graphene as the capacitor active material is almost translucent at $0.1 \mathrm{wt} \%$ of carbon, which broadens the scope of application for this composite to flexible photovoltaics or similar. A photo presented in Fig. 3a, c demonstrates the extent of elongation (notice that the elongation tests presented in Fig. 4b were taken using the universal mechanical testing instrument with standardized and calibrated loads). The images of other carbon-embedded hydrogels are presented in Figure S6-S7 (supporting information). Figure S6A shows an example of the scanning electron microscopy image of dry hydrogel with dispersed multi-walled carbon nanotubes. The carbon bundles are observed in the cross-sectional image (Figure S6B). 


\section{Water uptake in hydrogel}

Figure 4a demonstrates the percentage of water absorbed by dry MWCNT-based hydrogel as a function of time (sample was kept in a closed vessel at constant relative humidity and temperature). The electrode was weighed in time intervals and water uptake (WU) was calculated according to Eq. 2:

$\mathrm{WU}=\frac{m_{i}}{m_{0}} \cdot 100 \%$

where $m_{i}$ is the hydrogel mass at given time of measurement (in $\mathrm{g}$ ) and $m_{\mathrm{o}}$ is the constant mass (in $\mathrm{g}$ ) of dry hydrogel.

Overall, for all hydrogels containing the same amount of MWCNT, SWCNHs or graphene, the water uptake reached almost $50 \%$ of hydrogel original mass after 6 days of curing and remained constant when kept in atmosphere of constant humidity for unlimited number of days. The type of carbon did not influence the amount of adsorbed water. Furthermore, at higher carbon content, the mass of adsorbed water decreases with increasing amount of carbon (data not shown) and the proposed carbon loads were considered as optimal with regard to both elasticity and conductivity of the proposed electrodes. The water replenishment in these electrodes is reversible. The same results were acquired for the carbon-grafted-PPy embedded in hydrogel of the same composition.

\section{Stress-strain mechanical testing}

Figure $4 \mathrm{~b}$ shows elongation of hydrogels upon applied force. The experiments were performed with $1 \mathrm{kN}$ load of the cell transducer and all laminates had the same size and shape $(5 \mathrm{~cm} \times 2 \mathrm{~cm} \times 1 \mathrm{~cm})$. Generally, incorporation of carbons into hydrogel lowers the tensile strength and improves elongation. Varying the carbon content at low carbon loads $(0.1-2 \mathrm{wt} \%)$ did not affect the flexibility of hydrogels (can be related to homogeneous dispersion of carbon within hydrogel). For the same carbon load, MWCNT-embedded hydrogels are significantly more elastic than SWCNH- or graphene-based electrodes. Presumably, the degree of surface functionalization of carbons, and thus their hydrophobic-hydrophilic properties, results in various interactions with Nafion, polyacrylamide and water. This can be one of the reasons that causes the difference in elongation of the electrode. Another important factor that influences the elasticity of polyacrylamide-based hydrogels is air entrapped within these films, which affects their micro-porosity [57, 58]. Overall, the better mechanical strength was achieved for hydrogels containing well-dispersed nanostructured carbons as compared to pure hydrogel. This result agrees with observations made by other groups, revealing that local agglomeration of an active material within hydrogel strongly influenced the mechanical properties of laminates [59]. The stress-strain measurements showed a significant elongation, up to $1475.57 \%$ of original size, which makes these materials promising for applications such as light-weight and flexible electronics [60].

\section{Electrochemical analysis: conductivity and interfacial gravimetric capacitance upon elongation}

Nafion $117^{\circledR}$ and its derivatives exhibit proton conductivity owing to their chemical structure, resulting in the formation of percolated water channels [61]. Thus, ionic conductivity of hydrogel can be further improved by mixing it with Nafion $117^{\circledR}$, and both ionic components ( $\mathrm{KCl}$ dissolved in hydrogel and proton conductivity of Nafion) are strongly influenced by the amount of water in these electrolytes [62]. There are two mechanisms responsible for the ionic conductivity, one is called Grotthuss mechanism, and the second is a vehicular mechanism [63, 64]. The Grotthuss mechanism is based on the assumption that water molecules present in Nafion $117^{\circledR}$ can take up the proton, which results in the increase of energy for water molecules. Such energy change causes the rotation of water, leading to the transport of proton between adjacent molecules of water. This conductivity of ion is also called as hopping. Another form of proton conduction relies on vehicular mechanism, when ion is trapped between the solvent molecules (water) and moves with the solvent across percolated water channels, formed in the Nafion microstructure. Depending on an extent of Nafion hydratation, one of these conductivity pathways is predominant or, in many cases, both mechanisms take place simultaneously [65]. Additionally, the presence of nanostructured carbon in the hydrogel electrolyte results in an electronic conductivity [58]. The mixed ionic-electronic conductivity of such materials is particularly important for printed implantable biosensors, bioelectronics, neuronal prostheses, drug delivery or tissue engineering materials [58]. To calculate the conductivity, the electrochemical impedance spectroscopy (EIS) or electrochemical admittance spectroscopy (EAS) was carried out using a two-electrode testing cell, similar to the setup proposed by others [66-69].

The admittance spectra shown in Fig. 5a correspond to a resistor and capacitor in series, and the equivalent circuit used for data fitting is demonstrated in Fig. 5d. Accordingly, the impedance spectrum of these two elements in series is represented by the vertical line with an intercept crossing $Z^{\prime}$ axis at value of $R$ in the complex plane Nyquist plot (Fig. 5b, theoretical spectrum). Correspondingly, the admittance spectra of RC element in the series are represented by a semicircle with an intercept $Y^{\prime}=1 / R$ (Fig. 5c). The impedance $(Z=R+1 / i \omega C)$ or admittance $(Y=i \omega C / 1+i \omega R C$; theoretical admittance spectrum of $R C$ element in series is 

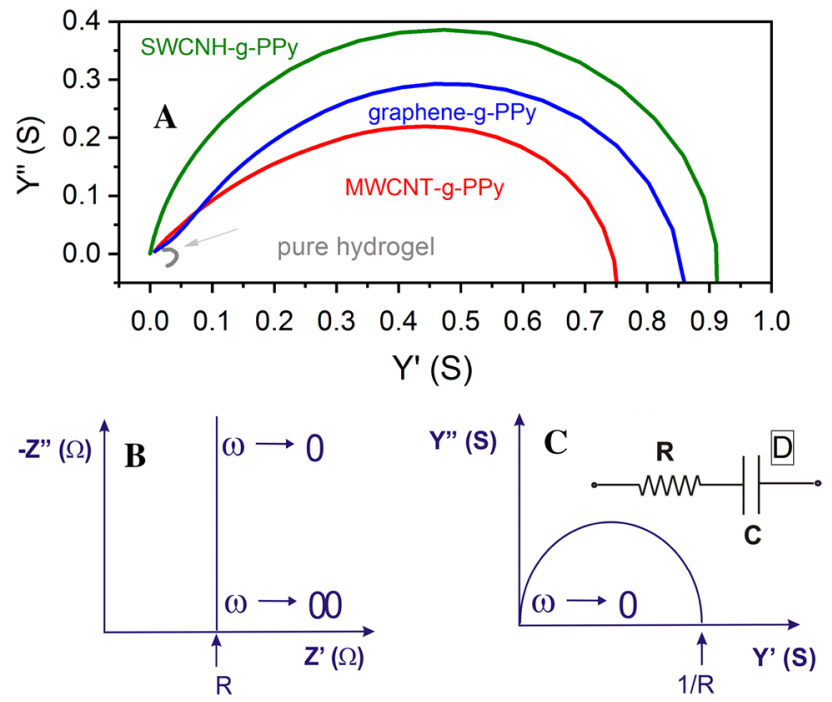

Fig. 5 Admittance spectra of pure hydrogel electrolyte and carbongrafted-polypyrrole films $\mathbf{a}$; theoretical Nyquist plot $\mathbf{b}$ and admittance c representing the electrical equivalent circuit $\mathbf{d}$ used for data fitting

demonstrated in Fig. 5c) is defined by a resistor $R$ that corresponds to the total resistivity of the film and was used to calculate the conductivity $(\sigma)$ standardized to their dimensions, $\sigma=(Y \times L) / A$ (where $Y$ is admittance in Siemens, $L$ is the length in $\mathrm{cm}$ and $A$ is the area of film in $\mathrm{cm}^{2}$; for conductivity tests taken without elongation). Since magnitude of both ionic and electronic resistance is the same for hydrated films (as shown in Fig. S10 for pure hydrogel, bare MWCNTs and the hydrogel-embedded carbon), it was impossible to distinguish between these two conductivity components from the admittance spectra shown in Fig. 5a. These tests were carried out at various elongation of laminates defined as the percentage of their initial length. Based on a fitting of the equivalent circuit (Fig. 5d), in steady-state conditions (without elongation), the pure hydrogel showed the lowest conductivity $\left(0.005-0.0075 \mathrm{~S} \mathrm{~cm}^{-1}\right)$, which was comparable to hydrogel electrolytes proposed by others, ranging typically within $1-2 \mathrm{mS} \mathrm{cm}^{-1}$ [71]. Likewise, the hydrogel containing only $0.1 \mathrm{wt} \%$ carbon (and carbon-grafted-PPy) revealed some improvement of conductivity due to the presence of electronically conductive phase (with the graphenegrafted-PPy offering the highest conductivity). Yet, due to a very low content of carbon composite, its contribution to the total resistance is very small. Upon elongation, the conductivity standardized only to the laminate thickness decreases within the same order of magnitude and is almost identical for all films containing grafted carbons at the highest elongation (150\%). This demonstrates that the stretching causes only a minor decrease in material conductivity and, therefore it can be used as a component of flexible energy storage devices. The conductivity of pure hydrogel is five time lower than that of the carbon-embedded in a steady

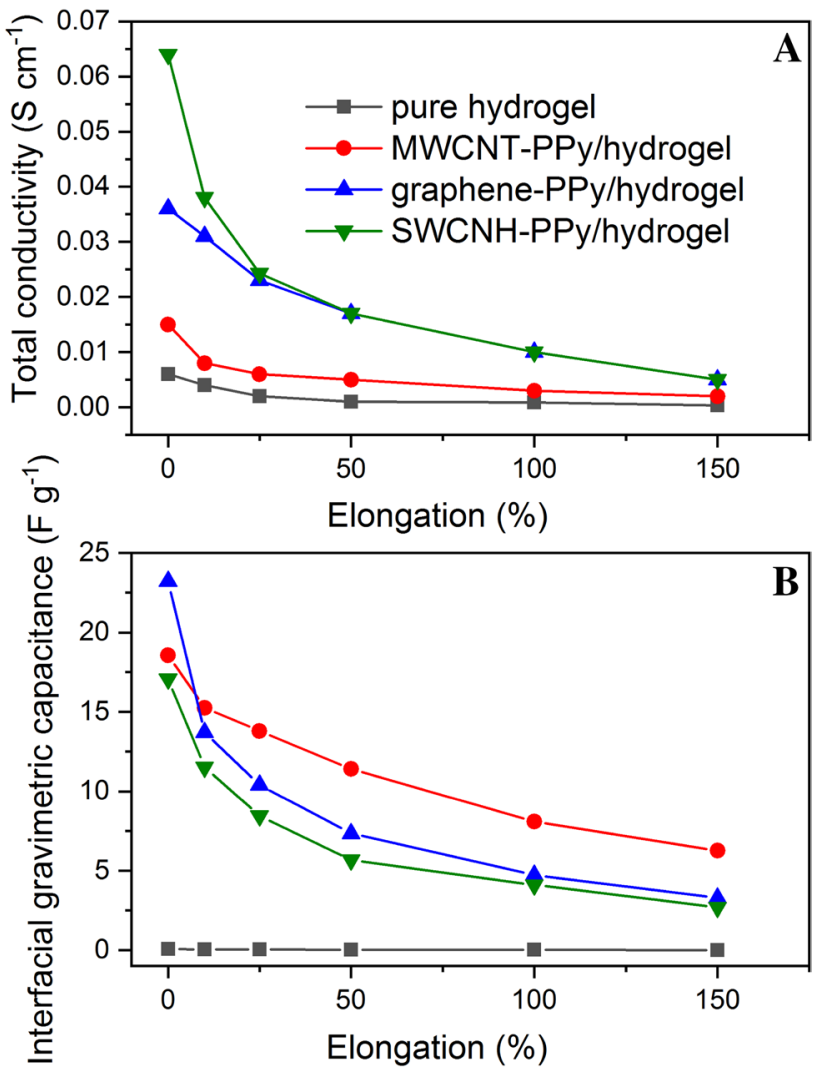

Fig. 6 Total conductivity a and interfacial gravimetric capacitance b upon elongation of pure and carbon-grafted-polypyrrole laminates (the latest synthesized by the oxidative radical polymerization [70])

state (Fig. 6a; 0 elongation), which is related to the contribution of electronic conductivity of carbon. This difference becomes insignificant upon elongation, probably due to an increasing distance between carbon particles (retreating the overall electron transfer).

The interfacial capacitance (element $C$ estimated from the fitting of admittance spectra with the equivalent circuit shown in Fig. 5d) of pAAm/pMBAA hydrogel with nanostructured carbons is significantly higher than that of pristine hydrogel (gravimetric capacitance is standardized to the mass of carbon and functionalized carbon). Since carbons (and carbon-grafted-polypyrrole) used in this study are known from their double layer and pseudo-capacitance, this is an obvious effect. The interfacial capacitance is, however, much lower than the current state-of-the-art capacitor materials (reaching hundreds of $\mathrm{F} \mathrm{g}^{-1}$ ). This is an important feature for specific applications such as using the hydrogelbased films as flexible current collectors in various energy storage or conversion devices (where they will not contribute to the capacitance of electrodes, while providing a sufficient electrical contact).

Considering hydrogels proposed in this study as a semisolid electrolyte for leakage-free energy systems, it has been 
shown by other groups that mixing similar hydrogels with conjugated polymers results in the modification of hydrogel microstructure and, as a consequence, in improvement of the electrode capacitance. For example, a nanostructured poly (aniline) embedded within the hydrogel electrolyte generates more porous composite as compared to the same pure hydrogel $[72,73]$. Its porosity facilitated the diffusion of redox active species and the transport of ions within electrolyte, leading to enhanced conductivity. Similar porosity effect has been reported for the graphene embedded in the hydrogel electrolyte, and also the conductivity and electrochemical stability of the composite electrode were improved, especially at high carbon loading [74]. The pAAm/pMBAA hydrogel without nanostructured carbons exhibited lower conductivity and stability.

\section{Zeta potential analyzed by rotating disk voltammetry}

Zeta potential at the surface of multilayers can be determined using spinning disk method that correlates the streaming potential measured between the two electrodes with the zeta potential, according to Eq. 3 [75]:

$\xi \cong \frac{1.96 \kappa v^{\frac{1}{2}}}{\varepsilon a \omega^{\frac{3}{2}}}\left(\frac{1}{2\left(1-\frac{z}{a}-\frac{1}{2\left(\frac{z^{2}}{a^{2}}+1\right)^{\frac{1}{2}}}\right.}\right) \theta_{\mathrm{S}}$

where $\kappa$ is the liquid conductivity $\left(\mathrm{S} \mathrm{cm}^{-1}\right.$, for $1 \mathrm{M}$ aqueous $\mathrm{KCl}$ this value was set as $12.90 \mathrm{mS} \mathrm{cm}{ }^{-1}$ [76]), $\nu$ is the kinematic viscosity of liquid (for $1 \mathrm{M} \mathrm{KCl}$ it is $1.19 \times 10^{-5} \mathrm{~m}^{2} \mathrm{~s}^{-1}$ [76]), $\varepsilon$ is the liquid permittivity (set as 4.68 [77]), $a$ is the disk radius $(0.005 \mathrm{~m}), z$ is the distance between the reference electrode and the RDE (kept constant as $0.057 \mathrm{~m}$ ), $\omega$ is the rotation rate in rpm (kept constant as $400 \mathrm{rpm} ; 6.66 \mathrm{~Hz}$ ), $\theta_{\mathrm{s}}$ is the measured streaming potential $(\mathrm{V})$ and is defined as the rest potential, also called open circuit potential (OCP), where no current load is applied to the electrode. Thus, the rest potential is a difference in the observed potential $\left(E_{\mathrm{OCP}}\right)$ and the standard potential or reference electrode $\left(E^{0}=222 \mathrm{mV}\right)$ :

$\theta_{\mathrm{s}}=E_{\mathrm{OCP}}-E^{0}$

In this study, we apply the rotating disk electrode and appropriate geometry between electrodes, allowing to minimize the contribution of the cell components to the measured potential, with a well-defined mass transport of reactants (Levich current), and taking into account the disk size with respect to its distance to the sensing electrode [78]. The interpretation of surface charge on a layer-by-layer electrode is more obvious, since each layer can be defined as the zone with finite thickness. In this experiment, the coating is a mixture of carbon, hydrogel and Nafion, and, therefore, the diffusion within this multicomponent mixture is more complex in terms of a shear plane that is related to streaming potential [75]. Also, for hydrated layers (hydrogel and Nafion), water content varies depending on the type of polymer. This strong fluctuation in water content generates changes in charge density; therefore, for the electrode immersed in aqueous solution, the zeta potential does not indicate the real density of fixed charged groups onto the surface. Taking into account these limitations, as well as the fact that the electrochemical response is measured from a soft layer, where static and hydrodynamic boundaries may not overlap, the proposed model (Eq. 3) also acquires the influence of Debye length, charge density, charge density profile, hydrodynamic penetration depth [79]. For the electrode consisting of several mixed components (such as our case), the streaming potential can be only analyzed qualitatively. The streaming potential acquired after $900 \mathrm{~s}$ for coated glassy carbon disk is shown in Fig. 7 and was used to estimate zeta potential (Table 2), according to Eq. 3. Overall, potentials obtained by this method are comparable for all coatings, except it is positive for the layer consisting only carbon and hydrogel. The change in the surface charge (from positive to negative) upon addition of Nafion to the mixture of carbon and hydrogel suggests that improvement of carbon dispersion within hydrogel can be related to change in the surface charge at the carbon-hydrogel interface (zeta potential). This result can

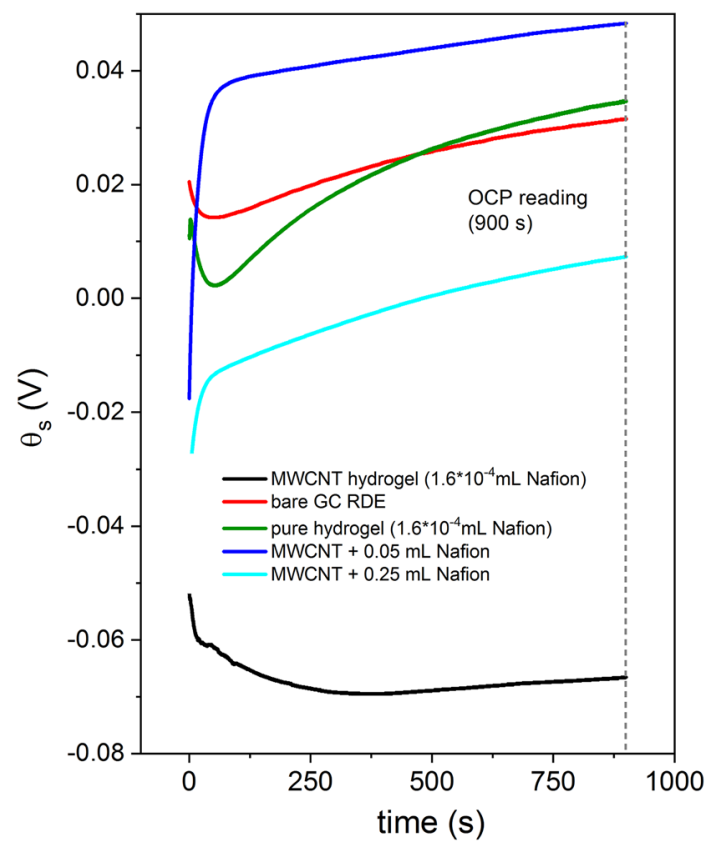

Fig. 7 The streaming potential for a pure hydrogel (green), bare rotating disk electrode (red) and MWCNT-embedded hydrogel (black) and without (blue, cyan) at different Nafion $117^{\circledR}$ content at $400 \mathrm{rpm}$ 
Table $2 \xi$-potential (zeta potential) for MWCNT with different Nafion $117^{\circledR}$ content, pure hydrogel, pure GC RDE and MWCNT-containing hydrogel at $400 \mathrm{rpm}$ (reading of OCP potential at $900 \mathrm{~s}$ )

\begin{tabular}{lcc}
\hline Electrode coating & $\xi$-Potential $(\mathrm{mV})$ & Streaming potential (V) \\
\hline Pure hydrogel & -0.167426932 & 0.03537859 \\
Bare glassy carbon & -0.147965867 & 0.031266319 \\
MWCNT + hydrogel + 0.25 mL Nafion & -0.036203757 & 0.007650131 \\
MWCNT + hydrogel + 5 mL Nafion & -0.228590276 & 0.048302872 \\
MWCNT + hydrogel & 0.314466082 & -0.066449086 \\
\hline
\end{tabular}

be only hypothesized, since it cannot be easily confirmed by other techniques that are suitable for layer-by-layer assemblies. In our case, such layer-by-layer experiment cannot be carried out for pure carbon exposed to the solution (carbon without a binder detaches from the electrode surface).

\section{Conclusions}

These studies demonstrate the effect of Nafion addition on dispersion of carbons within the poly (acrylamide) crosslinked with the $N, N^{\prime}$-methylenebisacrylamide hydrogel electrolyte. The microstructure, homogeneity, and water retention were considered as critical in fabrication of bendable and stretchable films with good electrochemical characteristics that can be used as current collectors or electrodes in flexible electronics. These laminates showed very good flexibility with a stretch reaching even $1475.57 \%$ of their original length, and regardless of the carbon load, the best elongation was observed to MWCNT-embedded hydrogels. Composites are translucent at a low carbon content, which expands a scope of their application to various photo-sensitive components. Water uptake of $47.20 \%$ per total mass of composite was observed for all electrodes tested in the closed humidity chamber, and the saturation of water can be reached within days, depending on the relative humidity and temperature. The Raman spectroscopy was used to analyze the carbon-polymer interactions and revealed that the graphene-based laminate is prone to agglomeration more than MWCNT or SWCNHs, as indicated by the intensity ratio of $I_{\mathrm{G}}$, apparent $/ I_{2 \mathrm{D} 1 \mathrm{~A}}$ signals. The FESEM and optical observations verified the uniform distribution of carbons (and grafted carbons) within hydrogel, owing to the presence of Nafion. Furthermore, these films were tested using electrochemical impedance and admittance spectroscopy, revealing that the addition of carbon generates electronic conductivity. As compared to pristine pAAm/pMBAA hydrogel $\left(0.002 \mathrm{~S} \mathrm{~cm}^{-1}\right)$, the conductivity of hydrogels with carbon- and the grafted carbon was improved, reaching $0.078 \mathrm{~S} \mathrm{~cm}^{-1}$ for the MWCNTs/hydrogel, $0.051 \mathrm{~S} \mathrm{~cm}^{-1}$ for the graphene/hydrogel and $0.052 \mathrm{~S} \mathrm{~cm}^{-1}$ recorded for the SWCNHs-embedded hydrogel.

In summary, pAAm/pMBAA-carbon films modified with Nafion were homogenous and demonstrated good mechanical and electrochemical characteristics, featuring their potential for applications in light-weight energy storage devices and in flexible or printed electronics.

Acknowledgements This work was carried out with the financial support of New Brunswick Innovation Foundation, and the Canada Foundation for Innovation JELF Grant\#36,874.

Open Access This article is distributed under the terms of the Creative Commons Attribution 4.0 International License (http://creativeco mmons.org/licenses/by/4.0/), which permits unrestricted use, distribution, and reproduction in any medium, provided you give appropriate credit to the original author(s) and the source, provide a link to the Creative Commons license, and indicate if changes were made.

\section{References}

1. Shi, Y., Peng, L., Yu, G.: Nanostructured conducting polymer hydrogels for energy storage applications. Nanoscale 30, 1279612806 (2015)

2. Arnaud, A., Coen, S., Jouve, A., Lelaidier, M., Perichaud, A.: Chemical modification of a polyacrylamide: enhanced decontamination of soils and surfaces after a nuclear accident. J. Radioanal. Nucl. Chem. Lett. 201, 213-223 (1995)

3. Gao, Y., Song, J., Li, S., Elowsky, C., Zhou, Y., Ducharme, S., Chen, Y.M., Zhou, Q., Tan, L.: Hydrogel microphones for stealthy underwater listening. Nat. Commun. 7, 12316 (2016)

4. Zhang, W., Liu, N., Cao, Y., Chen, Y., Zhang, Q., Lin, X., Qu, R., $\mathrm{Li}, \mathrm{H}$., Feng, L.: Polyacrylamide-polydivinylbenzene decorated membrane for sundry ionic stabilized emulsions separation via a facile solvothermal method. ACS Appl. Mater. Interfaces 8, 21816-21823 (2016)

5. Ahmed, E.M.: Hydrogel: preparation, characterization, and applications: a review. J. Adv. Res. 6, 105-121 (2015)

6. Guezennec, A.G., Michel, C., Bru, K., Touze, S., Desroche, N.: Transfer and degradation of polyacrylamide-based flocculants in hydrosystems: a review. Environ. Sci. Pollution Res. 22, 6390$6406(2015)$

7. Nazari Pour, S., Ghugare, S.V., Wiens, R., Gough, K., Liu, S.: Controlled in situ formation of polyacrylamide hydrogel on PET surface via SI-ARGET-ATRP for wound dressings. Appl. Surf. Sci. 349, 695-704 (2015)

8. Bu, H., Mikkelsen, S.R., English, A.M.: Characterization of a ferrocene-containing polyacrylamide-based redox gel for biosensor use. Anal. Chem. 67, 4071-4076 (1995)

9. Varaprasad, K., Raghavendra, G.M., Jayaramudu, T., Yallapu, M.M., Sadiku, R.: A mini review on hydrogels classification and recent developments in miscellaneous applications. Mater. Sci. Eng., C 79, 958-971 (2017)

10. Dey, A., Prakash, O., Sikder, A.K., Chattopadhyay, S., Shafeeuulla, A.: Recent advances in CNT/graphene based thermoelectric

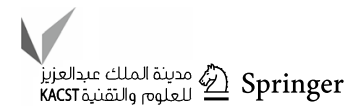


polymer nanocomposite: a proficient move towards waste energy harvesting. Renew. Sustain. Energy Rev. 53, 653-671 (2016)

11. White, B., Banerjee, S., Brien, S.O., Turro, N.J., Herman, I.P.: Zeta-potential measurements of surfactant-wrapped individual single-walled carbon nanotubes. J. Phys. Chem. C 111(37), 13684-13690 (2007)

12. Lee, J., Paik, U., Choi, J., Kim, K.K., Yoon, S., Lee, J., Kim, B., Kim, J.M., Park, M.H., Yang, C.W., An, K.H., Lee, Y.H., Di, V.: Dispersion stability of single-walled carbon nanotubes using Nafion in bisolvent. J. Phys. Chem. C 111, 2477-2483 (2007)

13. Rueckes, T., Kim, K., Joselevich, E., Tseng, G.Y., Lieber, C.M., Rueckes, T., Kim, K., Joselevich, E.: Carbon nanotube-based nonvolatile random access memory for molecular computing. Science 289, 94-97 (2017)

14. Itkis, M.E., Perea, D.E., Niyogi, S., Rickard, S.M., Hamon, M.A., $\mathrm{Hu}, \mathrm{H}$., Zhao, B., Haddon, R.C.: Purity evaluation of as-prepared single-walled carbon nanotube soot by use of solution-phase nearIR spectroscopy. Nano Lett. 3(3), 309-314 (2003)

15. Connell, M.J.O., Bachilo, S.M., Huffman, C.B., Moore, V.C., Strano, M.S., Haroz, E.H., Rialon, K.L., Boul, P.J., Noon, W.H., Ma, J., Hauge, R.H., Weisman, R.B., Smalley, R.E.: Band gap fluorescence from individual single-walled carbon nanotubes. Science 297(5581), 593-596 (2017)

16. Ponnamma, D., Sadasivuni, K.K., Grohens, Y., Guo, Q., Thomas, S.: Carbon nanotube based elastomer composites-an approach towards multifunctional materials. J. Mater. Chem. C. 2(40), 8446-8485 (2014)

17. Nadernezhad, A., Khani, N., Skvortsov, G.A., Toprakhisar, B., Bakirci, E., Menceloglu, Y., Unal, S., Koc, B.: Multifunctional 3D printing of heterogeneous hydrogel structures. Sci. Rep. 6, 33178 (2016)

18. Keplinger, C., Sun, J.-Y., Foo, C.C., Rothemund, P., Whitesides, G.M., Suo, Z.: Stretchable, transparent, ionic conductors. Science 30(341), 984-987 (2013)

19. Joddar, B., Garcia, E., Casas, A., Stewart, C.M.: Development of functionalized multi-walled carbon-nanotube-based alginate hydrogels for enabling biomimetic technologies. Sci. Rep. 6, 32456 (2016)

20. Sinani, V.A., Gheith, M.K., Yaroslavov, A.A., Rakhnyanskaya, A.A., Sun, K., Mamedov, A.A., Wicksted, J.P., Kotov, N.A., Arbor, A., Parkway, I.V.: Aqueous dispersions of single-wall and multiwall carbon nanotubes with designed amphiphilic polycations. J. Am. Chem. Soc. 127(10), 3463-3472 (2005)

21. Mickelson, E.T., Chiang, I.W., Zimmerman, J.L., Boul, P.J., Lozano, J., Liu, J., Smalley, R.E., Hauge, R.H., Margrave, J.L.: Solvation of fluorinated single-wall carbon nanotubes in alcohol solvents. J. Phys. Chem. B 103(21), 4318-4322 (1999)

22. Krstic, V., Duesberg, G.S.: Langmuir-Blodgett films of matrixdiluted single-walled carbon nanotubes. Chem. Mater. 10(9), 2338-2340 (1998)

23. Kuo, W., Lai, H., Chang, T., Wen, C.: Processing and failure behavior of carbon-nanotube composites in sheet forms. Polym. Composites 37(5), 1564-1571 (2016)

24. Estili, M., Liang, X., Ostrovidov, S.: Hybrid hydrogels containing vertically aligned carbon nanotubes with anisotropic electrical conductivity for muscle myofiber fabrication. Sci. Rep. 4, 4271 (2013)

25. Matarredona, O., Rhoads, H., Li, Z., Harwell, J.H., Balzano, L., Resasco, D.E.: Dispersion of single-walled carbon nanotubes in aqueous solutions of the anionic surfactant NaDDBS. J. Phys. Chem. B 107(48), 13357-13367 (2003)

26. Francisco, E., Cruz, D., Zheng, Y., Torres, E., Li, W., Song, W.: Zeta potential of modified multi-walled carbon nanotubes in presence of poly (vinyl alcohol) hydrogel. Int. J. Electrochem. Sci. 7, 3577-3590 (2012)
27. Kang, J., Hong, S., Kim, Y., Baik, S.: Controlling the carbon nanotube-to-medium conductivity ratio for dielectrophoretic separation. Langmuir 25(21), 12471-12474 (2009)

28. Zhang, H., Pan, J., He, X., Pan, M.: Zeta potential of Nafion molecules in isopropanol-water mixture solvent. Appl. Polym. Sci. 107, 3306-3309 (2008)

29. Hu, H., Yu, A., Kim, E., Zhao, B., Itkis, M.E., Bekyarova, E., Haddon, R.C.: Influence of the zeta potential on the dispersability and purification of single-walled carbon nanotubes. J. Phys. Chem. B 109(23), 11520-11524 (2005)

30. Online, V.A., Reinert, L., Zeiger, M., Presser, V.: Dispersion analysis of carbon nanotubes, carbon onions and nanodiamonds for their application as reinforcement phase in nickel metal matrix composites. RSC Adv. 5, 95149-95159 (2015)

31. Mamedov, A.A., Kotov, N.A., Prato, M., Guldi, D.M., Wicksted, J.P., Andreas, H.: Molecular design of strong single-wall carbon nanotube/polyelectrolyte multilayer composites. Nat. Mater. 1, 190-194 (2002)

32. Krause, B., Petzold, G., Pegel, S., Pötschke, P.: Correlation of carbon nanotube dispersability in aqueous surfactant solutions and polymers. Carbon 47, 602-612 (2009)

33. Hughes, M.P.: Dielectrophoretic behavior of latex nanospheres: low-frequency dispersion. J. Colloid Interface Sci. 250, 291294 (2002)

34. Kim, Y., Hong, S., Jung, S., Strano, M.S., Choi, J., Kim, Y.: Dielectrophoresis of surface conductance modulated singlewalled carbon nanotubes using catanionic surfactants. J. Phys. Chem. B 110, 1-5 (2008)

35. Balk, S., Usrejy, M., Rotkina, L., Strano, M.: Using the selective functionalization of metallic single-walled carbon nanotubes to control dielectrophoretic mobility. J. Phys. Chem. B 108, 15560-15564 (2004)

36. Yurekli, K., Mitchell, C.A., Krishnamoorti, R.: Small-angle neutron scattering from surfactant-assisted aqueous dispersions of carbon nanotubes. J. Phys. Chem. B 106, 9902-9903 (2004)

37. Engtrakul, C., Davis, M.F., Gennett, T., Dillon, A.C., Jones, K.M., Heben, M.J.: Protonation of carbon single-walled nanotubes studied using $13 \mathrm{C}$ and $1 \mathrm{H}-13 \mathrm{C}$ cross polarization nuclear magnetic resonance and Raman spectroscopies. J. Am. Chem. Soc. 127(49), 17548-17555 (2005)

38. Macintosh, A.R., Harris, K.J., Goward, G.R.: Structure and dynamics in functionalized graphene oxides through solid-state NMR. Chem. Mater. 28(1), 360-367 (2016)

39. Melchior, J., Wohlfarth, A., Portale, G., Kreuer, K.: About the interactions controlling Nafion's viscoelastic properties and morphology. Macromolecules 48(23), 8534-8545 (2015)

40. Zhao, H., Dong, Y., Jiang, P., Wang, G., Zhang, J.: Highly dispersed $\mathrm{CeO}_{2}$ on $\mathrm{TiO}_{2}$ nanotube: a synergistic nanocomposite with superior peroxidase-like activity. ACS Appl. Mater. Interfaces 7(12), 6451-6461 (2015)

41. Yang, F., Xin, L., Uzunoglu, A., Qiu, Y., Stanciu, L., Ilavsky, J., $\mathrm{Li}, \mathrm{W}$., Xie, J.: Investigation of the interaction between Nafion ionomer and surface functionalized carbon black using both ultrasmall angle X-ray scattering and cryo-TEM. ACS Appl. Mater. Interfaces 9(7), 6530-6538 (2017)

42. Rubatat, L., Diat, O., Spram, U.M.R., Cedex, G.: Stretching effect on Nafion fibrillar nanostructure. Macromolecules 40(26), 9455-9462 (2007)

43. Lu, Y., He, W., Cao, T., Guo, H., Zhang, Y., Li, Q., Shao, Z., Cui, Y., Zhang, X.: Elastic, conductive, polymeric hydrogels and sponges. Sci. Rep. 4, 5792 (2014)

44. Lewis, C.L., Meng, Y., Anthamatten, M.: Well-defined shapememory networks with high elastic energy capacity. Macromolecules 48(14), 4918-4926 (2015) 
45. Cohen, D., Mitra, J., Peterson, D.K., Maharbiz, M.M.: A highly elastic, capacitive strain gauge based on percolating nanotube networks. Nano Lett. 12(14), 1821-1825 (2012)

46. He, Q., Yu, M., Yu, D., Ding, Y., Dai, Z.: Significantly enhanced actuation performance of IPMC by surfactant-assisted processable MWCNT/Nafion composite. J. Bionic Eng. 10(3), 359-367 (2013)

47. Song, J., Han, O.H., Han, S.: Nanometer-scale water- and proton-diffusion heterogeneities across water channels in polymer electrolyte membranes. Angew. Chemie-Int. Ed. 54, 3615-3620 (2015)

48. Hashmi, S., Ghavaminejad, A., Obiweluozor, F.O., VatankhahVarnoosfaderani, M., Stadler, F.J.: Supramolecular interaction controlled diffusion mechanism and improved mechanical behavior of hybrid hydrogel systems of zwitterions and CNT. Macromolecules 45(24), 9804-9815 (2012)

49. Liu, Y., Su, Y., Chang, C., Wang, D., Lai, J.: Preparation and applications of Nafion-functionalized multiwalled carbon nanotubes for proton exchange membrane fuel cells. J. Mater. Chem. 20, 4409-4416 (2010)

50. Edri, E., Regev, O., Sheva, B.: "Shaken, Not Stable": dispersion mechanism and dynamics of protein-dispersed nanotubes studied via spectroscopy. Langmuir 25(18), 14454-14460 (2009)

51. Albrecht, A.C., Hutley, M.C.: Dependence of vibrational Raman intensity on wavelength of incident light. J. Chem. Phys. 55, 4438-4443 (1971)

52. Ember, K.J.I., Hoeve, M.A., Mcaughtrie, S.L., Bergholt, M.S., Dwyer, B.J., Stevens, M.M., Faulds, K., Forbes, S.J., Campbell, C.J.: Raman spectroscopy and regenerative medicine: a review. J. Regen. Med. 2, 1-9 (2017)

53. Kudin, K.N., Ozbas, B., Schniepp, H.C., Prud, R.K., Aksay, I.A., Car, R.: Raman spectra of graphite oxide and functionalized graphene sheets. Nano Lett. 8(1), 1-6 (2008)

54. Ferrari, A.C.: Raman spectroscopy of graphene and graphite: disorder, electron-phonon coupling, doping and nonadiabatic effects. Solid State Commun. 143(1-2), 47-57 (2007)

55. King, A.A.K., Davies, B.R., Noorbehesht, N., Newman, P., Church, T.L., Harris, A.T., Razal, J.M., Minett, A.I.: A new Raman metric for the characterization of graphene oxide and its derivatives. Sci. Rep. 6, 19491 (1)-19491 (6) (2016)

56. Graphene, B., Park, C., Giustino, F., Cohen, M.L., Louie, S.G.: Electron-phonon interaction and pairing mechanism in superconducting Ca-intercalated bilayer graphene. Sci. Rep. 6, 21414 (1)-21414 (6) (2008)

57. Sayyar, S., Gambhir, S., Chung, J., Officer, D.L., Wallace, G.G.: $3 \mathrm{D}$ printable conducting hydrogels containing chemically converted graphene. Nanoscale 5(9), 2038-2050 (2017)

58. Caldorera-Moore, M., Peppas, N.A.: Micro- and nanotechnologies for intelligent and responsive biomaterial-based medical systems. Adv. Drug Deliv. Rev. 61(15), 1391-1401 (2009)

59. Dispenza, C., Lo Presti, C., Belfiore, C., Spadaro, G., Piazza, S.: Electrically conductive hydrogel composites made of polyaniline nanoparticles and poly( $N$-vinyl-2-pyrrolidone). Polymer 47, 961-971 (2006)

60. Yang, P., Sun, P., Mai, W.: Electrochromic energy storage devices. Biochem. Pharmacol. 19, 394-402 (2016)

61. Chiu, Y.-C., Kocagöz, S., Larson, J.C., Brey, E.M.: Evaluation of physical and mechanical properties of porous poly (ethylene glycol)-co-(L-lactic acid) hydrogels during degradation. PLoS One 8(4), e60728 (2013)

62. Tong, X., Tian, N., Wu, W., Zhu, W., Wu, Q., Cao, F., Yan, W., Yaroslavtsev, A.B.: Preparation and electrochemical performance of tungstovanadophosphoric heteropoly acid and its hybrid materials. J. Phys. Chem. C 117(7), 3258-3263 (2013)

63. Zhang, S., Kang, L., Wang, X., Tong, L., Yang, L., Wang, Z., Qi, K., Deng, S., Li, Q., Bai, X., Ding, F., Zhang, J.: Arrays of horizontal carbon nanotubes of controlled chirality grown using designed catalysts. Nature 543, 234-238 (2017)

64. Singh, R.K., Kunimatsu, K., Miyatake, K., Tsuneda, T.: Experimental and theoretical infrared spectroscopic study on hydrated Nafion membrane. Macromolecules 49(17), 621-6629 (2016)

65. Wada, H., Nohara, S., Furukawa, N., Inoue, H., Sugoh, N., Iwasaki, H., Morita, M., Iwakura, C.: Electrochemical characteristics of electric double layer capacitor using sulfonated polypropylene separator impregnated with polymer hydrogel electrolyte. Electrochim. Acta 49(27), 4871-4875 (2004)

66. Inagaki, M., Konno, H., Tanaike, O.: Carbon materials for electrochemical capacitors. J. Power Sources 195, 7880-7903 (2010)

67. Pissis, P., Kyritsis, A.: Electrical conductivity studies in hydrogels. Solid State Ionics 97, 105-113 (1997)

68. Chen, H., Yang, F., Hu, R., Zhang, M., Ren, B., Gong, X., Ma, J., Jiang, B., Chen, Q., Zheng, J.: A comparative study of the mechanical properties of hybrid double-network hydrogels in swollen and as-prepared states. J. Mater. Chem. B. 4(35), 58145824 (2016)

69. Mawad, D., Lauto, A., Wallace, G.G.: Conductive polymer hydrogels. In: Kalia S. (ed.) Polymeric Hydrogels as Smart Biomaterials, Springer Series on Polymer and Composite Materials. Springer International Publishing, Switzerland, pp. 19-44 (2016). https://doi.org/10.1007/978-3-319-25322-0_2

70. Radtke, M., Ignaszak, A.: Grafting of the carbon allotropes and polypyrrole via a Kevlar-type organic linker: the correlation of carbon structure/morphology with electrochemistry of the composite electrode. Mat. Renew. Sustain. Energy 6, 1-15 (2017)

71. Lu, F., Gao, X., Dong, B., Sun, P., Sun, N., Xie, S., Zheng, L.: Nanostructured proton conductors formed via in situ polymerization of ionic liquid crystals. ACS Appl. Mater. Interfaces 6(24), 21970-21977 (2014)

72. Cho, S., Shin, K., Jang, J.: Enhanced electrochemical performance of highly porous supercapacitor electrodes based on solution processed polyaniline thin films. ACS Appl. Mater. Interfaces 5(18), 9186-9193 (2013)

73. Ke, Q., Wang, J.: Graphene-based materials for supercapacitor electrodes-a review. J. Materiomics 2(1), 37-54 (2016)

74. Ates, M., Cinar, D., Caliskan, S., Gecgel, U., Uner, O., Candan, I.: Active carbon/graphene hydrogel nanocomposites as a symmetric device for supercapacitors, Fullerenes. Nanotub. Carbon Nanostructures 24, 427-434 (2016)

75. Ferriz-Manas, M., Schlenoff, J.B.: Zeta potential of polyelectrolyte multilayers using the spinning disk method. Langmuir 30, 8776-8783 (2014)

76. Kestin, J., Shankland, I.R., Paul, R.: The viscosity of aqueous $\mathrm{KCl}$ solutions in the temperature range $25-200{ }^{\circ} \mathrm{C}$ and the pressure range 0.1-30 Mpa. Int. J. Thermophys. 2, 301-314 (1981)

77. Robinson, M.C., Hollis Hallett, A.C.: The static dielectric constant of $\mathrm{NaCl}, \mathrm{KCl}$, and $\mathrm{KBr}$ at temperatures between 4.2 and $300^{\circ} \mathrm{K}$. Can. J. Phys. 44, 2211-2230 (1966)

78. Sides, P.J., Prieve, D.C.: Surface conductivity and the streaming potential near a rotating disk shape sample. Langmuir 29, 13427-13432 (2013)

79. Duval, J.F.L., Kuttner, D., Werner, C., Zimmermann, R.: Electrohydrodynamics of soft polyelectrolyte multilayers: point of zerostreaming current. Langmuir 27, 10739-10752 (2011)

Publisher's Note Springer Nature remains neutral with regard to jurisdictional claims in published maps and institutional affiliations. 